\title{
A Comparison of Transverse Palatal Width in Adult Untreated Cleft Palate Patients with Normal Adult Palates: A Pilot Study
}

\author{
Shenjuti Chowdhury¹, Shahid Aziz², Richard D. Bloomstein ${ }^{3}$, Thomas J. Cangialosi4 \\ ${ }^{1}$ Former resident in Private Practice of Orthodontics in Astoria, New York, USA \\ ${ }^{2}$ Assistant Dean and Professor of Oral and Maxillofacial Surgery, Rutgers University School of Dental Medicine, Newark, USA \\ ${ }^{3}$ Associate Professor of Orthodontics, Rutgers University School of Dental Medicine, Newark, USA \\ ${ }^{4}$ Professor and Chair Department of Orthodontics, Rutgers University School of Dental Medicine, Newark, USA \\ Email: shenjutichowdhury@gmail.com, azizsr@sdm.rutgers.edu,bloomsrd@sdm.rutgers.edu, cangitj@sdm.rutgers.edu
}

How to cite this paper: Chowdhury, S., Aziz, S., Bloomstein, R.D. and Cangialosi, T.J. (2021) A Comparison of Transverse Palatal Width in Adult Untreated Cleft Palate Patients with Normal Adult Palates: A Pilot Study. Open Journal of Orthopedics, 11, 126-137. https://doi.org/10.4236/ojo.2021.114012

Received: February 24, 2021

Accepted: April 13, 2021

Published: April 16, 2021

Copyright $\odot 2021$ by author(s) and Scientific Research Publishing Inc. This work is licensed under the Creative Commons Attribution International License (CC BY 4.0).

http://creativecommons.org/licenses/by/4.0/

(c) (i) Open Access

\begin{abstract}
Objective: The purpose of this pilot study is to compare the transverse palatal widths in untreated adult cleft palate patients with normal adult patients. Methods and Materials: The study was conducted in Bangladesh recruiting 10 patients with adult sized untreated cleft palate and 15 patients with normal adult sized palates. The control group was comprised of 7 males and 8 females with a mean age of $30.5 \pm 4.4$ years. The affected group comprised of 7 males and 3 females with a mean age $17 \pm 3.3$ years. Alginate impressions of the maxillary arch were taken and poured into plaster dental casts. The inter-canine, inter-premolar and intermolar widths were measured to evaluate the maxillary growth pattern in patients with un-operated cleft palate. Due to the small sample size, both independent T-test and Mann Whitney non-parametric tests were performed to analyze the statistical significance of the data. Results: According to both the T-test and Mann Whitney non-parametric tests, the inter-premolar width including both the first and second premolars was statistically significantly smaller in the affected group with $\mathrm{p}$ values of 0.003 and 0.00 respectively. There was no significant difference in the inter-canine width between the affected and control group due to the variable canine position in cleft palate patients. Due to small sample size, no significant difference in the intermolar width between the affected and control group could be established. Conclusion: The interpremolar width is significantly smaller in patients with adult sized cleft palates than individuals with normal adult sized palates.
\end{abstract}




\section{Keywords}

Cleft, Palate, Adult, Transverse, Dimension

\section{Introduction}

Cleft lip and palate is one of the most common congenital craniofacial deformities affecting the midface region and results in functional, esthetic and psychosocial disturbances. According to Wyszynski et al. [1], non-syndromic clefts affect approximately 1 in 1000 Caucasian newborns, 3.6/1000 Native American newborns, 2.1/1000 Japanese births, 1.7/1000 Chinese births, and 0.3/1000 African American births. Wyszynski reported that less than 3\% of all cases of CL/P represent a recognized syndrome. The Majority of Cleft lip/palate patients have non-syndromic clefts which have complex traits because they do not exhibit a classic Mendelian pattern of inheritance but do show strong familial aggregation with genetic heterogeneity within and between populations. Vanderas [2] reported that the incidence of cleft lip with/without cleft palate ranged from 0.71 to 1.29 per 1000 while the incidence of isolated cleft palate ranged from 0.19 to 0.83 per 1000 births. Males have a higher incidence of both cleft lip and cleft lip/palate.

In mammals, the palate consists of the bony hard palate anteriorly, which is essential for feeding and speech, and the soft palate posteriorly, which is crucial for closing the airway during swallowing. ${ }^{3}$ Palatogenesis is the developmental process that leads to the formation of the hard and soft palate which is initiated in the sixth week and completed by 12 weeks of gestation [3]. In mammals, facial development begins with the formation of the five facial prominences: the frontonasal prominence, a pair of maxillary prominences and a pair of mandibular prominences [3] [4]. As the face develops the frontonasal process divides into the mesial and nasal processes forming the nostrils. Fusion between the medial nasal process and the maxillary process forms the upper lip and the primary palate [3] [4]. The secondary palate arises as paired outgrowths from the maxillary process initially growing vertically on the sides of the developing tongue [3] [4]. As the mandible grows antero-posteriorly the tongue moves downward eventually allowing the vertical palatal shelves to re-orient horizontally above the dorsum of the tongue during palatal shelf elevation [4]. At this point, the paired palatal shelves grow towards the midline and eventually fuse. The secondary palate also fuses anteriorly with the primary palate and anterodorsally with the nasal septum [3] [4].

There has been extensive research focus on maxillary development in cleft lip and palate patients. However, research in the development of the maxilla in cleft palate patients without surgery is very limited because of the lack of an ample number of patients with untreated cleft palates. The difficulty of gathering a large enough sample group is due to the few cases of adult untreated cleft pa- 
lates. Furthermore, most research focuses on cephalometric analysis instead of dental arch morphology, which is crucial for surgical as well as orthodontic treatment planning [5].

Current literature provides conflicting information about maxillary growth in untreated cleft palate patients. According to Mars and Houston, maxillary growth is normal in cleft palate patients [6]. However, many other studies have stated that there is an intrinsic shortage of palatal tissue [7] [8] [9]. The tissue deficiency appears greater in untreated cleft palate patients compared with patients who were operated at an earlier age, emphasizing the effect of stretching and muscular action on the development of the prolabium [10].

Examination of maxillary development in adult sized cleft palate patients without surgery enables the study of the normal maxillofacial growth of cleft palate patients without the intervention of surgery or orthodontics [5]. Transverse palatal width is crucial in planning surgery because scar tissue from surgical treatment can lead to transverse constriction of the maxilla as well as malposed teeth [7]. Therefore, better understanding of the transpalatal development via measurement of the arch width in untreated cleft palate patients will allow surgeons and orthodontists to determine their treatment objectives specific to patient growth patterns leading to more successful outcomes.

The purpose of this prospective study is to compare the transverse palatal width in untreated adult cleft palate patients with normal adult palates. According to Bishara et al. [11], the intercanine and intermolar width reaches its maximum at age 13 years in both males and females. Lux et al. [12], also reported that the growth rate in intermolar width reaches its peak in both males and females at age 13 years. For the purposes of this study, adult sized palate is defined as those in individuals who are at least 13 years of age.

This study was conducted in Bangladesh during Smile Bangladesh semi-annual mission trips over a span of 2 years. Bangladesh is a nation of approximately 150 million people with an estimated 300,000 people with untreated cleft lip and palate. A majority of these affected individuals, live in rural areas and are poor [13]. Furthermore, Bangladesh with only a handful of plastic surgeons and few oral and maxillofacial surgeons lacks the resources to have a central cleft lip and palate rehabilitation center geared towards providing comprehensive multidisciplinary care [13] [14]. Furthermore, many people in the rural areas are ignorant of the fact that clefts are a congenital deformity and that they can be repaired. Many of these unfortunate individuals spend their entire lives with untreated cleft lip and palate. In developed nations like the United States, it is very rare to find a study sample of untreated cleft patients since in this country when a child is born with a cleft deformity they are placed under the care of a Cleft team for rehabilitation. Surgical mission trips such as Smile Bangladesh raise awareness regarding cleft deformities and provide care to many individuals who would have lived in darkness for the rest of their lives Other charitable organizations such as Smile Train [15], and Operation Cleft [16], have helped to raise 
awareness regarding cleft deformities, educate parents regarding prenatal care, stress the importance of folic acid in reducing the incidence of cleft deformities and repair thousands of cleft lips and palates.

Current literature is in agreement that there is a maxillary deficiency in cleft palate patients. However, there is disagreement on whether the maxillary deficiency is intrinsic or it is secondary to scaring from surgery. Therefore, the study of the transverse growth in cleft palate individuals without surgical intervention or orthodontics is important in determining the true maxillary growth pattern in cleft palate patients.

\subsection{Clinical Significance of the Study}

To enable the study of the maxillary growth of untreated cleft palate patients without the intervention of surgery or orthodontics and Dentofacial orthopedics.

\subsection{Objective}

To compare the transverse maxillary width of untreated adult sized cleft palate patients with that of normal adult sized palates.

\subsection{Null Hypothesis}

There is no difference in the transverse palatal width between untreated adult sized cleft palates and normal adult sized palates.

\subsection{Study Timeline}

The study will be conducted over a span of 2 years comprised of trips to Bangladesh every March and November.

\subsection{Study Population}

\subsubsection{Affected Group}

\section{Inclusion criteria:}

1) Minor children/adult population over the age of 13 who present with untreated cleft palate.

2) English or Bangla speaking.

\section{Exclusion criteria:}

1) Deciduous teeth remaining.

2) History of orthodontics.

3) Pregnancy.

\subsubsection{Control Group}

\section{Inclusion criteria:}

1) Healthy minor children/adult groups over the age of 13 years.

2) Complete maxillary dentition excluding third molars.

3) English or Bangla speaking. 


\section{Exclusion criteria:}

1) Anterior/posterior crossbite.

2) History of orthodontics.

3) Orthognathic surgeries.

4) Apparent oral habits.

5) Pregnancy.

\subsection{Recruitment}

The subjects will be recruited from Update Dental College, Aichi Nagar, Khayertek, Tturag, Dhaka-1711, Bangladesh.

\subsection{Consent and Approval}

Patients were informed of the study, its purpose along with risks and benefits. Consent for the study was obtained from patients prior to surgery and for the control sample as well. Any identifiable Protected Health Informationwas removed from the medical records or dental casts. Each patient was assigned a numeric identifier.

The study protocol was reviewed and approved by the Ethics Committee (Rutgers School of Dental Medicine, Newark, NJ; eIRBApproval no. 2013003646). March 26, 2014.

\section{Materials and Methods}

A dental impression was made with impression material according to the requirements for a complete denture with adequate edge extension and distinct anatomic landmarks [1]. The dental impressions were poured up with hard plaster stone. See Figure 1. The following measurements were made on the dental cast: 1) intercanine maxillary arch width measured as the transverse distance between the left and right canines at the gingival margin; 2) Interpremolar maxillary arch width measured between the left and right first premolar at the gingival margin; 3) Interpremolar maxillary arch width measured between the left and right second premolar at the gingival margin; 4) intermolar width was measured as the distance between the right and left mesiolingual cusps of the first molars at the gingival margin. See Figure 2 and Table 1.

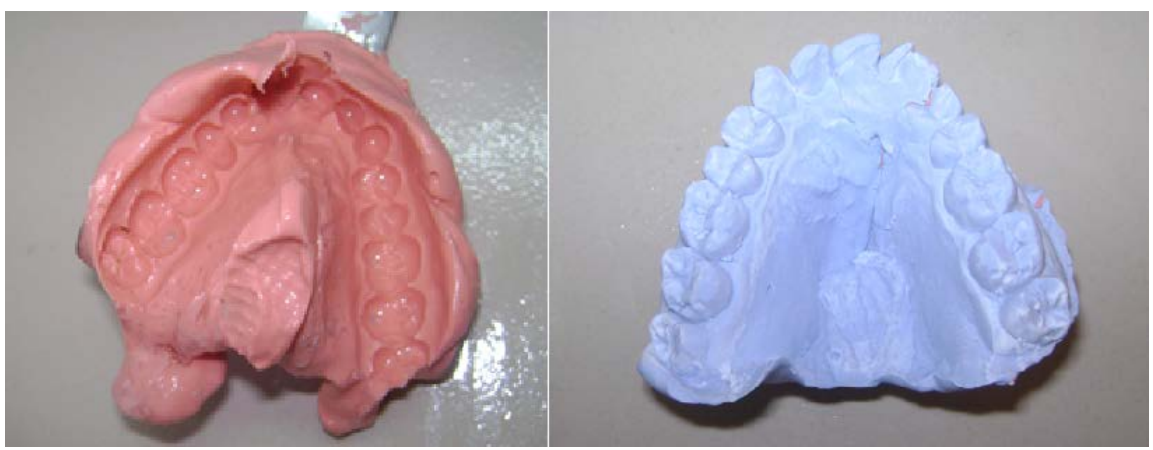

Figure 1. Alginate impression and hard plaster stone model. 


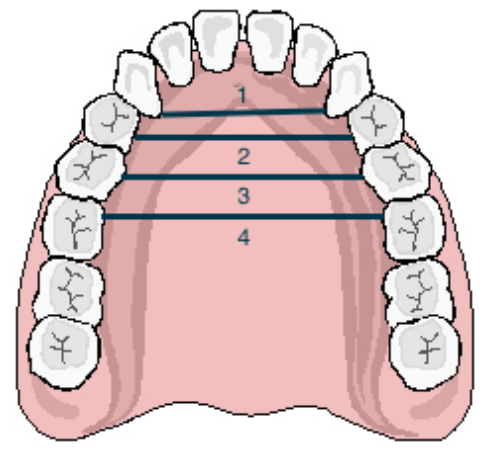

Figure 2. Schematic diagram showing the measurements made on the casts.

Table 1. Dental measurements.

\begin{tabular}{|c|c|}
\hline Measurement & Definition \\
\hline U6-U6 (mm) & $\begin{array}{l}\text { Intermolar width was measured as the distance between the right and } \\
\text { left mesiolingual cusps of the first molars at the gingival margin }\end{array}$ \\
\hline U5-U5 (mm) & $\begin{array}{l}\text { Interpremolar maxillary arch width measured between the left and } \\
\text { right secondpremolar at the gingival margin }\end{array}$ \\
\hline $\mathrm{U} 4-\mathrm{U} 4(\mathrm{~mm})$ & $\begin{array}{l}\text { Interpremolar maxillary arch width measured between the left and } \\
\text { right first premolar at the gingival margin }\end{array}$ \\
\hline U3-U3 (mm) & $\begin{array}{c}\text { Intercanine maxillary arch width measured between the left and } \\
\text { right canines at the gingival margin }\end{array}$ \\
\hline
\end{tabular}

\section{Statistical Analysis}

The data was analyzed using Microsoft Excel 2007 and IBM SPSS Software (Version 21.0, Chicago, IL) for clinical significance. Intra-class correlation coefficient (ICC) was used to assess both intra-examiner reliability and inter-examiner reliability, using the Two-Way mixed and absolute agreement model. Due to the small sample size both independent sample T-test and non-parametric MannWhitney tests were performed to analyze the clinical significance of the collected data.

\section{Results}

The study was able to recruit only ten subjects for the affected group due to the limitation of finding patients with adult sized unrepaired cleft palates. Fifteen subjects were recruited for the control groups as well. The control group comprised 7 males and 8 females with a mean age of $30.5 \pm 4.4$ years (Table 2). The affected group comprised 7 males and 3 females with a mean age $17 \pm 3.3$ years (Table 2).

Based on the data, the mean values in the control group for the transverse segments U6-U6, U5-U5, U4-U4 and U3-U3 were $36.3 \mathrm{~mm}$ (std. $\mathrm{dev}=1.9 \mathrm{~mm}$ ), $34.3 \mathrm{~mm}$ (std. dev $=1.7 \mathrm{~mm}$ ), $28.9 \mathrm{~mm}$ (std. $\mathrm{dev}=2.4 \mathrm{~mm}$ ) and $25.3 \mathrm{~mm}$ (std. $\mathrm{dev}=4.1 \mathrm{~mm}$ ) respectively. The mean values in the affected group for the trans- 
verse segments U6-U6, U5-U5, U4-U4 and U3-U3 were $34.2 \mathrm{~mm}$ (std. dev = 3.0), $31.2 \mathrm{~mm}$ (std. $\mathrm{dev}=2.5 \mathrm{~mm}$ ), $24.6 \mathrm{~mm}$ (std. dev = 2.7) and $23.9 \mathrm{~mm}$ (std. $\mathrm{dev}=2.1 \mathrm{~mm}$ ) respectively (Table 3 ).

Intra-class correlation coefficient (ICC) was used to assess both intra-examiner reliability and inter-examiner reliability, using the Two-Way mixed and absolute agreement model (Table 4). According to the analysis, the intra-examiner coefficient correlations for Examiner 1 and examiner 2 were 0.998 and 0.999 respectively. The average inter-examiner coefficient correlation for all values was 0.998 . All the correlation coefficients showed excellent correlations, which indicate that all intra and inter measurements were very reliable.

The mean difference between the control and affected group for U6-U6 transverse measurement shows that the palatal width at the first permanent molars was greater in the control than the affected group. However, based on the independent T-test the difference between the two groups was not statistically significant with a $\mathrm{p}$ value of 0.05 (Table 5 and Table 6). According to the independent T-tests comparing the means of the means of the transverse segments between the affected and control groups, there was significant difference between the palatal transverse widths between the U5-5 and U4-4 with p-values of 0.002 and 0.002 respectively (Table 5 and Table 6 ).

Table 2. Gender and age distribution of control and affected groups.

\begin{tabular}{|c|c|c|c|c|}
\hline Subject & $\begin{array}{c}\text { Control Group } \\
\text { Gender }\end{array}$ & Age (Years) & $\begin{array}{c}\text { Affected Group } \\
\text { Gender }\end{array}$ & Age (Years) \\
\hline 1 & Female & 34 & Male & 25 \\
\hline 2 & Female & 28 & Male & 14 \\
\hline 3 & Female & 22 & Male & 16 \\
\hline 4 & Male & 33 & Female & 16 \\
\hline 5 & Female & 31 & Male & 19 \\
\hline 6 & Female & 27 & Male & 17 \\
\hline 7 & Male & 37 & Male & 15 \\
\hline 8 & Male & 32 & Female & 14 \\
\hline 9 & Male & 36 & Female & 14 \\
\hline 10 & Male & 35 & Male & 20 \\
\hline 11 & Male & 32 & & \\
\hline 12 & Male & 32 & & \\
\hline 13 & Female & 26 & & \\
\hline 14 & Female & 29 & & \\
\hline 15 & Female & 24 & & \\
\hline
\end{tabular}


Table 3. Measurements of transverse segments recorded on casts of control group.

\begin{tabular}{|c|c|c|c|c|c|c|c|c|}
\hline & Control & Group & & & Experimental & Group & & \\
\hline Subjects & U6-U6 (mm) & U5-U5 (mm) & $\mathrm{U} 4-\mathrm{U} 4(\mathrm{~mm})$ & U3-U3 (mm) & U6-U6 (mm) & U5-U5 (mm) & $\mathrm{U} 4-\mathrm{U} 4(\mathrm{~mm})$ & U3-U3 (mm) \\
\hline 01 & 36.54 & 35.02 & 29.67 & 25.39 & 30.74 & 27.48 & 20.73 & missing left \\
\hline 02 & 36.02 & 35.23 & 28.74 & 25.86 & 35.13 & 32.36 & 25.88 & 24.68 \\
\hline 03 & 33.45 & 31.00 & 25.96 & 22.57 & 36.4 & 31.52 & 25 & 23.81 \\
\hline 04 & 38.21 & 37.68 & 33.52 & 27.76 & 32.64 & 30.07 & 21.93 & 22.18 \\
\hline 05 & 33.92 & 31.70 & 26.87 & 24.13 & 33.27 & 30.56 & 25.08 & 19.90 \\
\hline 06 & 34.2 & 33.26 & 27.54 & 23.82 & 33.08 & 31.48 & 23.26 & 32.08 \\
\hline 07 & 42.62 & 38.50 & 30.75 & 26.70 & 36.41 & 33.91 & 26.03 & 21.75 \\
\hline 08 & 39.71 & 37.26 & 31.9 & 25.74 & 35.21 & 32.35 & 25.25 & 26.47 \\
\hline 09 & 37.47 & 35.42 & 29.14 & 27.43 & 32.8 & 30.93 & 29.4 & 26.13 \\
\hline 10 & 33.25 & 33.04 & 24.78 & 21.16 & 36.01 & 31.51 & 23.25 & 18.10 \\
\hline 11 & 37.89 & 34.46 & 28.87 & 25.76 & & & & \\
\hline 12 & 34.96 & 34.31 & 29.75 & 26.88 & & & & \\
\hline 13 & 31.56 & 28.98 & 25.06 & 22.98 & & & & \\
\hline 14 & 37.9 & 34.97 & 30.43 & 27.06 & & & & \\
\hline 15 & 37.46 & 33.94 & 31.03 & 27.64 & & & & \\
\hline Mean & 36.34 & 34.32 & 28.93 & 25.39 & 34.169 & 31.22 & 24.581 & 23.90 \\
\hline
\end{tabular}

Table 4. Intra-class correlation coefficient.

\begin{tabular}{|c|c|c|c|}
\hline & $\begin{array}{l}\text { Examiner1-measure1 } \\
\text { vs. } \\
\text { Examiner1-measure2 }\end{array}$ & $\begin{array}{l}\text { Examiner2-measure1 } \\
\text { vs. } \\
\text { Examiner2-measure2 }\end{array}$ & $\begin{array}{l}\text { Examiner1-average } \\
\text { vs. } \\
\text { Examiner2-average }\end{array}$ \\
\hline U6-U6 & 0.998 & 0.999 & 0.995 \\
\hline U5-U5 & 0.993 & 0.996 & 0.995 \\
\hline U4-U4 & 0.996 & 0.996 & 0.997 \\
\hline U3-U3 & 0.990 & 0.993 & 0.987 \\
\hline All & 0.998 & 0.999 & 0.998 \\
\hline
\end{tabular}

Based on the mean difference, the palatal width in the affected group in the U3-U3 region is smaller than the control group. However, according to both the independent T-test $\mathrm{p}$ value of 0.46 and Mann Whitney non-parametric test $\mathrm{p}$-value of 0.32 , there is no significant difference between the transverse palatal width in the U3-U3 segment in both the control and affected groups (Table 5 and Table 6). In cleft palate patients the position of the canine on the cleft side is variable and in many cases missing as well and that adds to the great variation in our findings regarding the intercanine width comparison between normal individuals and those with cleft palate. 
Table 5. Independent T-test results comparing the means of the transverse segment measurements in the affected and control groups.

\begin{tabular}{cccc}
\hline Group & Mean $(\mathrm{mm})$ & Std. deviation $(\mathrm{mm})$ & p-value \\
\hline U6-U6 affected & 34.2 & 1.9 & 0.05 \\
Control & 36.3 & 2.9 & \\
U5-U5 affected & 31.2 & 1.7 & 0.003 \\
Control & 34.3 & 2.5 & 0.000 \\
U4-U4 affected & 24.6 & 2.4 & \\
Control & 28.9 & 2.5 & 0.25 \\
U3-U3 affected & 23.9 & 4.1 & \\
Control & 25.3 & 2.0 & \\
\hline
\end{tabular}

Table 6. Mann-Whitney test results comparing the means of the transverse segment measurements in the affected and control groups.

\begin{tabular}{|c|c|c|c|c|}
\hline & Null Hypothesis & Test & Sig. & Decision \\
\hline 1 & $\begin{array}{l}\text { The distribution of U6U6 } \mathrm{mm} \text { is the } \\
\text { same across catagories of Group }\end{array}$ & $\begin{array}{l}\text { Independent Samples } \\
\text { Mann-Whitney U Test }\end{array}$ & $0.036^{1}$ & $\begin{array}{l}\text { Reject the null } \\
\text { hypothesis }\end{array}$ \\
\hline 2 & $\begin{array}{l}\text { The distribution of U5U5 } \mathrm{mm} \text { is the } \\
\text { same across catagories of Group }\end{array}$ & $\begin{array}{l}\text { Independent Samples } \\
\text { Mann-Whitney U Test }\end{array}$ & $0.001^{1}$ & $\begin{array}{l}\text { Reject the null } \\
\text { hypothesis }\end{array}$ \\
\hline 3 & $\begin{array}{l}\text { The distribution of } \mathrm{U} 4 \mathrm{U} 4 \mathrm{~mm} \text { is the } \\
\text { same across catagories of Group }\end{array}$ & $\begin{array}{l}\text { Independent Samples } \\
\text { Mann-Whitney U Test }\end{array}$ & $0.001^{1}$ & $\begin{array}{l}\text { Reject the null } \\
\text { hypothesis }\end{array}$ \\
\hline 4 & $\begin{array}{l}\text { The distribution of U3U3 } \mathrm{mm} \text { is the } \\
\text { same across catagories of Group }\end{array}$ & $\begin{array}{l}\text { Independent Samples } \\
\text { Mann-Whitney U Test }\end{array}$ & $0.155^{1}$ & $\begin{array}{l}\text { Retain the null } \\
\text { hypothesis }\end{array}$ \\
\hline
\end{tabular}

Asymptomatic significances are displayed. The significance level is $0.05 ;{ }^{1}$ Exact significance is displayed for this test.

\section{Discussion}

To the best of our knowledge this is the first study comparing the transverse palatal widths of unrepaired adult sized cleft palates with normal adult sized palates in a homogenous population. With the advent of several charitable organizations organizing surgical mission trips in Bangladesh the population with unrepaired cleft palates has been greatly reduced. Hence, it was very difficult to recruit affected individuals for this study meeting all the inclusion criteria.

The biggest challenge conducting research in Bangladesh is the remoteness of the site, which, in turn, limits availability of research materials at the study site. Another great hurdle is the language barrier because people in different regions speak different dialects. Furthermore, a majority of the patients recruited at the surgical site had very minimal prior dental treatment, which made patient instruction and education very challenging. Additionally, the impression-taking technique is demanding incleft palate patients because impression material could flow into the nasal cavity and may cause discomfort as well as interference 
when removing the impression from the patient's mouth.

According to the results, there was no significant difference in the traverse palatal widths between the affected and the control group in the U3-U3 region. This may be explained by the fact that the canine on the cleft side is often times missing or ectopically erupted [17]. This could account for the great variation observed in the results. Based on our findings, the transverse palatal width is significantly smaller in the affected individuals in the premolar region (U4-U4 and U5-U5) in comparison to the control group. This is supported by the findings of Ruan [7], Derijcke [8] and Diah [9], according to whom there is an intrinsic shortage of palatal tissue in unrepaired cleft palate individuals.

There was no significant difference in the transverse palatal width in the inter-molar (U6-U6) region between the affected and control group based on the independent $\mathrm{T}$-test $\mathrm{p}$ value of 0.05 . However, according to the non-parametric Mann Whitney test, the transverse palatal width in the inter-molar region (U6-U6) is significantly smaller than the control group. The discrepancy between the two test results may be attributed to the small sample size. Therefore, further research with a larger sample is needed to get better insight into the matter. Future studies can also be conducted comparing the transverse palatal widths in surgically repaired cleft lip/palate patients with untreated cleft lip/palate patients, which might alter approach and timing of surgery.

\section{Conclusions}

1) There was no significant difference in the intercanine width between the affected and control group due to the variable canine position in cleft palate patients.

2) The interpremolar width is significantly smaller in patients with adult sized cleft palates than individuals with normal adult sized palates.

3) No significant difference in the intermolar width between the affected and control group could be established based on the independent T-test. However, according to the non-parametric Mann Whitney test, the transverse palatal width in the intermolar region was significantly smaller than the control group.

4) A larger sample size is needed for more conclusive results.

\section{Disclosure}

The abstract of this paper was presented at the 2016 Annual Session of the American Association of Orthodontists in Orlando Florida as an E-Poster.

\section{Conflicts of Interest}

The authors declare no conflicts of interest regarding the publication of this paper.

\section{References}

[1] Wyszynski, D., Beaty, T. and Maestri, N. (1996) Genetics of Nonsyndromic Oral Clefts Revisited. The Cleft Palate-Craniofacial Journal, 33, 406-417. 
https://doi.org/10.1597\%2F1545-1569_1996_033_0406_gonocr_2.3.co_2

[2] Vanderas, A. (1987) Incidence of Cleft Lip, Cleft Palate, and Cleft Lip and Palate among Races: A Review. Cleft Palate Journal, 24, 216-225.

[3] Bush, J. and Jiang, R. (2011) Palatogenesis: Morphogenetic and Molecular Mechanisms of Secondary Palate Development. Development, 139, 231-243.

https://doi.org/10.1242/dev.067082

[4] Meng, L., Bian, Z., Torensma, R. and Hoff, J. (2009) Biological Mechanisms in Palatogenesis and Cleft Palate. Journal of Dental Research, 88, 22-33.

https://doi.org/10.1177\%2F0022034508327868

[5] Ye, B., Ruan, C., Hu, J., Yang, Y., Ghosh, A., Jana, S. and Zhang, G. (2010) A Comparative Study on Dental-Arch Morphology in Adult Unoperated and Operated Cleft Palate Patients. Journal of Craniofacial Surgery, 21, 811-815.

https://doi.org/10.1097/SCS.0b013e3181d879fa

[6] Mars, M. and Houston, W.J. (1990) A Preliminary Study of Facial Growth and Morphology in Unoperated Male Unilateral Cleft Lip and Palate Subjects Over 13 Years of Age. Cleft Palate Journal, 27, 7-10. https://doi.org/10.1597\%2F1545-1569_1990_027_0007_apsofg_2.3.co_2

[7] Ye, B., Ruan, C., Hu, J., Yang, Y., Thomas, J. and Zhang, G. (2012) A Comparative Study on the Measurements of Palatal Shelf Area and Gradient for Adult Patients with Unoperated Cleft Palate. The Cleft Palate Craniofacial Journal, 49, 561-565. https://doi.org/10.1597\%2F09-236

[8] Derijcke, A., Kuijpers-Jagtman, A., Lekkas, C., Hardjowasito, W. and Latief, B. (1994) Dental Arch Dimensions in Unoperated Adult Cleft Palate Patients: An Analysis of 37 Cases. Journal of Craniofacial Genetics and Developmental Biology, 14, 69-75.

[9] Diah, E., Lo, L.-J., Huang, C.-S., Sudjatmiko, G., Susanto, I. and Chen, Y.-R. (2007) Maxillary Growth of Adult Patients with Unoperated Cleft: Answer to Debates. Journal of Plastic, Reconstructive \& Aesthetic Surgery, 60, 407-413. https://doi.org/10.1016/j.bjps.2006.10.004

[10] Ortiz-Monasterio, F., Serrano, A., Barrera, G., Rodriguez-Hoffman, H. and Vinageras, E. (1966) A Study of Untreated Adult Cleft Palate Patients. Plastic and Reconstructive Surgery, 38, 36-41. https://doi.org/10.1097/00006534-196607000-00007

[11] Bishara, S., Ortho, D., Jakobsen, J., Treder, J. and Nowak, A. (1997) Arch Width Changes from 6 Weeks to 45 Years of Age. American Journal of Orthodontics and Dentofacial Orthopedics, 111, 401-409. https://doi.org/10.1016/S0889-5406(97)80022-4

[12] Lux, C. (2004) Transverse Development of the Craniofacial Skeleton and Dentition between 7 and 15 Years of Age-A Longitudinal Postero-Anterior Cephalometric Study. European Journal of Orthodontics, 26, 31-42. https://doi.org/10.1093/ejo/26.1.31

[13] Aziz, S., Rhee, S. and Redai, I. (2009) Cleft Surgery in Rural Bangladesh: Reflections and Experiences. Journal of Oral and Maxillofacial Surgery, 67, 1581-1588. https://doi.org/10.1016/j.joms.2008.11.021

[14] Paul, A., Spauwen, P., Spronk, C. and Niemeijer, R. (2007) Cleft Lip and Palate Treatment in Bangladesh. European Journal of Plastic Surgery, 29, 267-270. https://doi.org/10.1007/s00238-006-0089-3

[15] Operation Cleft (2016) Free Cleft Repair Surgery for Children in Bangladesh. http://operationcleft.org.au/ 
[16] Wikipedia (2016) Operation Smile. https://en.wikipedia.org/wiki/Operation_Smile

[17] Akcam, M.O., Evirgen, S., Uslu, O. and Memikoglu, U.T. (2010) Dental Anomalies in Individuals with Cleft Lip and/or Palate. European Journal of Orthodontics, 32, 207-213. https://doi.org/10.1093/ejo/cjp156 